things seem to be moving in the right direction, albeit slowly. For example, the level of funding for research has increased; in 2001, Giuliano Amato's government devoted an additional 450 million euros (US\$388 million) to research, using money from an auction of telecommunications licences although this measure has not been repeated for 2002 by Silvio Berlusconi's government. Italy invests about one-third of the percentage of gross domestic product that Japan spends on research, although resources are starting to be distributed on a more rational basis, involving peer review. However, Palombini points out that simply putting more money into a system that contains too many people who do not share the same values of merit and competition is no guarantee of success.

Most Italian universities are still capable of producing highly talented scientists. Burton Richter, Nobel prizewinner and professor of physics at Stanford University in California, knows the Italian system well, being a member of an international committee charged with reviewing the Italian National Institute for Nuclear Physics. As he writes in this book, he does not understand how Italy can afford the social cost of this continuing brain drain, particularly in the absence of a brain gain from other countries, which is hampered by the bureaucratic and parochial selection system in Italy, as well as by poor funding. I don't understand it either. But reading this book gave me a better idea of the causes and consequences of this process.

Roberto Battiston is at the Sezione INFN,

Via Pascoli, I-016121 Perugia, Italy.

\section{The answer lies in the soil}

\section{Understanding Soil Change:}

Soil Sustainability over Millennia, Centuries, and Decades

by Daniel D. Richter Jr \& Daniel Markewitz Cambridge University Press: 2001. 272 pp. $\mathfrak{E} 47.50, \$ 69.95$

\section{David Schimel}

This marvellous little book tells the story of southeastern US ecosystems from the perspective of soil changes over timescales of decades, centuries and millennia. I was delighted with the author's organizing of processes into timescales. This is a natural way of thinking about soil and ecosystem processes, but is more often given lip-service than actually used as an organizing principle. In this case, it works, both because the soil processes - from weathering and geomorphic evolution, through leaching and decomposition - fall into this framework, and because human impacts also change on these timescales.

The first part of the book provides a clear and conceptual overview of the elements of soil science, and their links to human management of soils. The authors demonstrate clearly that sustaining soil "health" is essential to sustaining human societies, and that soil change is linked to historical change in human economy. They then introduce the system that is the focus of their study, the Calhoun Experimental Forest, a property in South Carolina procured during the regional collapse of unsustainable agricultural practices of the southern United States in the first part of the twentieth century.

In the second section, which addresses millennial processes, they review pedogenesis (soil formation) globally and in the old soils of their target region. Here we begin to see the fruit of the sustained research effort at the Calhoun site, as the processes leading to the acid soils of the region are carefully documented in terms of geomorphic, geochemical and biological dynamics. Key findings include the role of biologically generated acidity in attacking the soil's primary minerals.

The third section addresses the centennial timescale. It includes a history of the agricultural development of the South, drawing attention to the little-known intensive maize cultivation system of the indigenous Americans before the arrival of Europeans. The authors provide a detailed analysis of the sustainability of this system, and the human and landscape conditions that allowed its success. They then provide a unique perspective on the 'Old South's' cotton economy in terms of agricultural management and the biogeochemistry of the cotton economy. The discussion on the legacy of cotton growth in today's soils makes fascinating reading, blending political and economic history with soil chemistry. The authors conclude that the previous two centuries of agriculture have affected soils to great depth (two metres) and will continue to affect ecosystems well into the future.

The authors next describe a period over recent past decades during which agricultural land over huge areas in the southeastern United States has reverted from farmland to forest. This is the timescale of the Calhoun experiment and describes in detail the recovery of carbon and nitrogen in soils of the regrowing forest. The rapid and massive response of soil to the re-establishment of forests is astonishing. The Calhoun soils re-establish soil acidity, carbon content and a functioning nitrogen cycle that can effectively retain inputs. Likewise, phosphorus chemistry changes as a result of the increase in organic matter and the associated effects of acidity on the inorganic chemistry of this element. The degree of knowledge of soil processes documented for

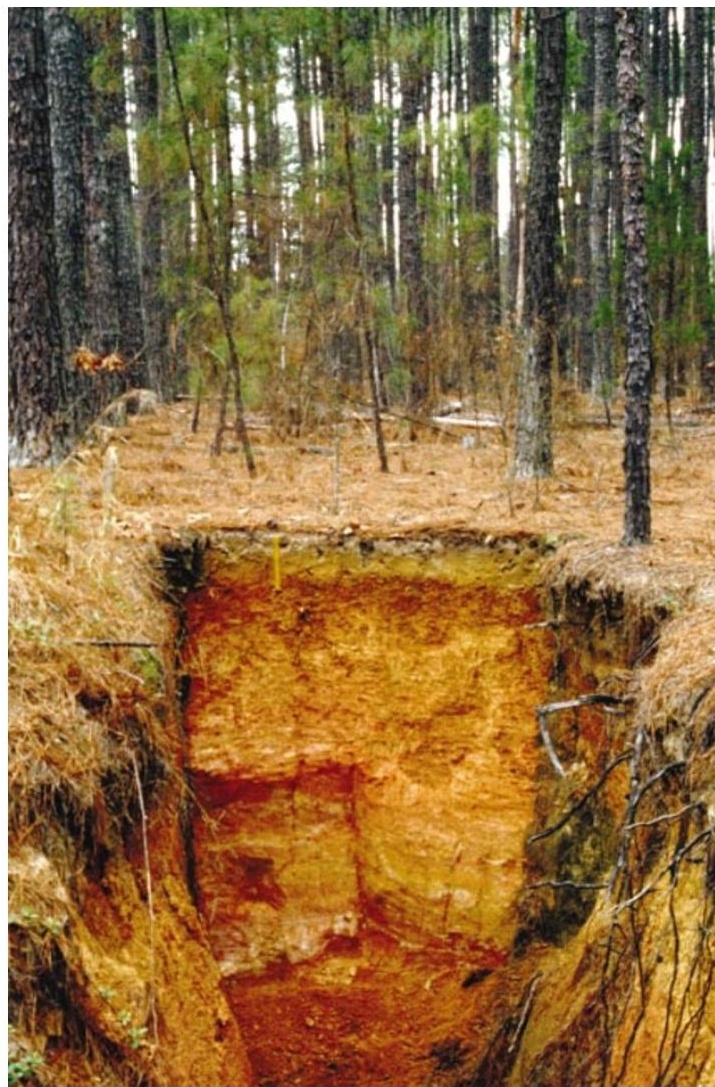

Down to earth: the Calhoun experiment has studied soil-ecosystem changes over 43 years.

this site is equalled for only a very small number of other locations.

The final section of the book outlines a research strategy based on a proposed network of long-term soil-research sites and careful experimental design. This proposal, in which the authors argue for a research paradigm based on replicated manipulative experiments, is founded on experience both at the Calhoun site and in other long-term ecosystem studies. While the utility, value and rigour of this approach need no comment, the authors themselves have shown the additional value of a perspective that takes into account the dynamics and legacies of millennial and centennial landscape processes. Decades-long experiments, using conventional manipulation and replicated plots, cannot address the role of slow pedogenic and landscape-scaled processes. For this, the analytical paradigms of the geophysical sciences could be useful, as they can address entities (such as ecosystems) for which replication is a challenging problem, which are difficult to manipulate, and which respond on long timescales. The dependence on fisherian statistics and classical experimental design in soil science is a legacy from agronomy, not altogether suited to largescale, long-term processes.

This book fills an important niche in the biogeochemical literature, and not only as a regional case study. Forest ecosystems play a large part in global processes, affecting the 